\title{
A FILOSOFIA DA CIÊNCIA E O CONCEITO DE CONHECIMENTO ANTERIOR
}

\author{
THE PHILOSOPHY OF SCIENCE AND THE CONCEPT OF \\ BACKGROUND KNOWLEDGE
}

\author{
Marcos Rodrigues da Silva* \\ Debora Domingas Minikoski*
}

Recebido: 07/2017

Aprovado: 10/2017

\begin{abstract}
Resumo: Uma das categorias filosóficas considerada de modo quase consensual como fundamental para a compreensão da atividade científica é a categoria denominada de "conhecimento anterior": um conhecimento consolidado na literatura científica e que serve de base para a formulação e aceitação de novas teorias científicas. Porém, ao relativo consenso acerca da importância do conhecimento anterior não se segue um aprofundamento conceitual a respeito de seu estatuto filosófico. Uma consulta tanto à literatura da filosofia da ciência quanto a alguns registros históricos da ciência mostra que a expressão "conhecimento anterior" pode ser melhor compreendida como um conceito geral que abriga, em seu interior, tipos específicos de emprego do conhecimento anterior. O objetivo deste artigo é o de apontar a pertinência de uma taxonomia do conceito de conhecimento anterior, considerando as contribuições da filosofia da ciência e da história da ciência.

Palavras-chave: Conhecimento Anterior; Inferência da melhor explicação; História da Ciência.

Abstract: One of the philosophical categories considered almost consensual as essential to understanding of scientific activity is the one called "background knowledge": a knowledge established in the scientific literature and which works as the foundation for the formulation and acceptance of new scientific theories. However, to the consensus about the importance of background knowledge does not follow a carefully conceptual survey about its philosophical status. An investigation both the literary production of philosophy of science and to some historical records of science shows that the phrase "background knowledge" can be better understood as a general concept, a one that covers specific kinds of employment of background knowledge. The purpose of this article is to point out the relevance of a taxonomy of background knowledge's concept, take in account the contributions of philosophy of science and history of science.
\end{abstract}

Keywords: Background Knowledge; Inference to the best explanation; History of Science.

\section{Introdução}

Uma das categorias filosóficas considerada de modo quase consensual como fundamental para a compreensão da atividade científica é a categoria denominada de "conhecimento anterior"1. Em linhas gerais a ideia básica desta noção é a de que cientistas produzem suas hipóteses e teorias a partir do conhecimento disponível em seu campo de atuação: o conhecimento anterior. Do mesmo modo, quando da avaliação comunitária de uma hipótese, cientistas tendem a considerar a relação que essa hipótese estabelece com o conhecimento anterior consolidado. A ideia geral é a de que a confiabilidade de

\footnotetext{
* Doutor em Filosofia pela Universidade de São Paulo. Professor do Departamento de Filosofia da Universidade Estadual de Londrina. Área de especialidade: filosofia da ciência.

** Professora da Unopar (Londrina/PR) e mestranda no Mestrado em Filosofia da Universidade Estadual de Londrina.
} 
um conhecimento já consolidado é um guia para sabermos se estamos, quando da produção de uma novidade, diante de uma produção científica igualmente confiável. Assim, tal noção parece ser de fundamental importância para a compreensão de alguns aspectos da ciência.

É interessante perceber, no entanto, que ao relativo consenso acerca da importância do conhecimento anterior não se segue um aprofundamento conceitual a respeito de seu estatuto filosófico, sendo habitual a mera identificação da categoria (eventualmente seguida de uma exemplificação histórica). Aliás, um contundente indício bibliométrico deste não aprofundamento pode ser percebido em consultas a dicionários de filosofia e dicionários de filosofia da ciência: não localizamos um único verbete chamado "conhecimento anterior"2; no máximo a expressão foi empregada em outros verbetes, sugerindose com isso que a noção deve simplesmente ser aceita sem uma reflexão mais profunda acerca de seu significado e portanto "conhecimento anterior" deve significar simplesmente um conhecimento consolidado na literatura científica.

O problema com esta definição é que sua generalidade não capta a extensão do uso do conceito tanto em seus diferentes empregos conceituais por parte dos filósofos quanto em sua aplicação identificada por meio da história da ciência; pois, mesmo que a expressão "conhecimento anterior" signifique de fato o emprego de um conhecimento consolidado, a verdade é que existem diversas formas de tal emprego. Uma consulta tanto à literatura da filosofia da ciência quanto a alguns registros históricos da ciência mostra que a expressão "conhecimento anterior" pode ser melhor compreendida como um conceito geral que abriga, em seu interior, tipos específicos de emprego do conhecimento anterior. Assim, o objetivo deste artigo é o de apontar a pertinência de uma taxonomia do conceito de conhecimento anterior, considerando as contribuições da história da ciência.

Em nossa pesquisa, identificamos três tipos de uso do conhecimento anterior: a) o uso do conhecimento anterior empregado a partir de um paradigma ou tradição de pesquisa; b) analogia como conhecimento anterior; c) o uso do conhecimento anterior tendo por base a resolução de um problema previamente definido.

Na primeira seção deste artigo situamos o leitor na concepção filosófica do conceito de "conhecimento anterior", bem como seus diferentes usos filosóficos. A segunda seção apresenta os três tipos de emprego do conhecimento anterior, bem como sugere possibilidades de desenvolvimento da discussão a respeito de cada tipo identificado.

1. Identificando a noção de conhecimento anterior na filosofia da ciência. A noção de conhecimento anterior tem sido amplamente aceita e desenvolvida na filosofia da ciência, e portanto sua identificação na literatura não é exatamente uma tarefa complexa. 
Ela é claramente identificável na obra de Thomas Kuhn. Para Kuhn, pressuposto um paradigma condutor das investigações científicas gerais em um campo, o desenvolvimento específico das pesquisas emprega a estrutura do paradigma (leis, técnicas de experimentação, ontologia etc). No que diz respeito aos problemas com fatos, as teorias de um paradigma têm a função de aumentar a precisão do mesmo a partir tanto de um refinamento empírico do comportamento das entidades que o paradigma diz existir, quanto de um refinamento teórico para solucionar as ambiguidades do paradigma (KUHN, 2000, p. 46-52).

Uma concepção bastante semelhante pode ser encontrada em Larry Laudan, com sua proposição de uma tradição de pesquisa, a qual é, por assim dizer, um correlato da noção kuhniana de paradigma. Laudan assim define uma tradição de pesquisa: "um conjunto de pressuposições gerais acerca das entidades e processos num domínio de estudo e acerca dos métodos apropriados que devem ser utilizados para a investigação dos problemas e para a construção de teorias neste domínio" (1977:81). Com isso, uma tradição de pesquisa determina, para teorias específicas, que tipos de objetos existem no mundo (pressupostos ontológicos) e qual a metodologia deve ser empregada para lidar com os objetos descritos pelas teorias (pressupostos metodológicos).

A filosofia do realismo cientifico é também uma ótima exemplificação da importância do conhecimento anterior. Um importante argumento realista para descrever a prática científica é o bem conhecido argumento da inferência da melhor explicação, o qual inclui a noção de conhecimento anterior, e que pode ser assim apresentado: a) uma evidência $E$ deve ser explicada; b) H explica melhor $\mathrm{E}$ do que outras hipóteses rivais; c) uma hipótese $\mathrm{H}$ está de acordo com o conhecimento anterior estabelecido; d) conclusão: podemos acreditar na verdade de $\mathrm{H}^{3}$. A ideia fundamental que guia os realistas em sua defesa do conhecimento anterior é a de que a profusão dos dados experimentais à disposição de um cientista o confundiria caso ele não se orientasse a partir da estrutura teórica presente na ciência e já previamente consolidada; assim, o que direciona o cientista em sua explicação dos dados é o conhecimento anterior verdadeiro (BOYD, 1985, p. 9; PSILLOS, 2000, p. 47; LEPLIN, 1997, p. 116; GIERE, 1999, p. 193). Do mesmo modo, no momento da aceitação de uma hipótese, cientistas tendem a considerar a hipótese em questão a partir do conhecimento anterior consolidado e verdadeiro (LIPTON, 2010, p. 322; LIPTON, 2004, p. 56). Além disso, o uso filosófico da noção de conhecimento anterior é considerado pelo realista Alexander Bird como uma estratégia interessante para mostrar que, em casos de disputas entre hipóteses, não apenas a hipótese vitoriosa pode ser considerada verdadeira, mas igualmente as outras podem ser inapelavelmente abandonadas como "refutadas" (BIRD, 2014, p. 378). 
Uma outra contribuição importante foi dada pelo filósofo Paul Thagard, em sua discussão dos critérios para a escolha de teorias. Um destes critérios é o da analogia ${ }^{4}$. A analogia deve ser entendida, de acordo com Thagard, como o estabelecimento de uma relação explicativa de uma nova hipótese com o conhecimento anterior já consolidado e portanto ela é um critério essencialmente explicativo (THAGARD, 1978, p. 90). Assim, na formulação de sua hipótese, o cientista, por razões explicativas, vincula sua hipótese a algum conhecimento anterior (ou mesmo a vários conhecimentos anteriores) e, se tal vinculação estabelecer uma relação entre sua hipótese e o conhecimento anterior, o cientista está diante de uma forte razão para propor sua própria hipótese. $\mathrm{Na}$ concepção de Thagard o que se pretende, com uma analogia, é apresentar o desconhecido a partir de algo já conhecido (THAGARD, 1978, p. 91).

A tradição empirista não se exime quanto à importância do conhecimento anterior. O filósofo empirista construtivo Bas van Fraassen, discutindo o conceito de explicação científica, propôs que uma explicação não fosse considerada como um argumento, mas como uma resposta a uma "questão por que" (uma why-question). Quando se pergunta por que um determinado fenômeno ocorre de um certo modo, pressupõe-se que este fenômeno efetivamente ocorra. Este pressuposto é importante pois a avaliação da teoria que forneceu a resposta para uma questão será feita à luz do conhecimento anterior (VAN FRAASSEN, 2007, p. 256). Tal conhecimento anterior, entretanto, e diferente dos realistas, não contém teorias verdadeiras, mas teorias empiricamente adequadas (verdadeiras apenas no que diz respeito a fenômenos observáveis) (LADYMAN et. al, 2000, p. 68).

A perspectiva sócio-construtivista também apresenta uma caracterização de conhecimento anterior. Bruno Latour, por exemplo, faz uso de uma expressão conhecida em cibernética para expressar sua concepção a respeito de um conhecimento consolidado: a expressão caixa preta. $\mathrm{Na}$ área de onde a expressão foi retirada, caixa preta é usada para designar uma máquina ou conjunto de comandos que são muito complexos e sobre os quais não é preciso saber nada, com exceção daquilo que entra e daquilo que sai da caixa (LATOUR, 2000, p.14). Uma caixa preta é, portanto, algo que já não é mais questionado, trata-se de um conhecimento que está pronto e em pleno uso por parte da comunidade científica: ao se fecharem, as caixas-pretas se tornam conhecimento tácito, usado como pressuposto para o desenvolvimento da pesquisa em uma determinada área. Nesse sentido, as caixas pretas se constituem como conhecimento anterior no qual as pesquisas de desenvolvimento de uma área se fundam.

Percebe-se portanto que a noção de conhecimento anterior está presente, de um modo ou outro, na filosofia da ciência ${ }^{5}$, sendo portanto algo que pode ser considerado não problemático do ponto de vista de sua identificação. Contudo, 
como vimos, ainda que convergente, tal identificação admite sub-divisões. Quando empregamos a concepção historiográfica de Kuhn e Laudan, o conceito de conhecimento anterior fica vinculado aos paradigmas e tradições de pesquisa. O raciocínio analógico, porém, não depende da existência de um paradigma. Um outro uso de conhecimento anterior que não depende de um paradigma, e além disso não é analógico, é aquele feito a partir de uma generalização confiável para a resolução de um problema.

Assim, aparentemente estamos diante de várias formas de emprego de conhecimento anterior. Na seção seguinte, com o apoio de alguns exemplos históricos, procuraremos apresentar um complemento taxonômico para a noção de conhecimento anterior.

2. A noção de conhecimento anterior: uma proposta inicial de uma taxonomia. Apresentamos, a seguir, os três tipos de emprego do conhecimento anterior que extraímos de registros históricos da ciência: a) o uso do conhecimento anterior empregado a partir de um paradigma; b) analogia como conhecimento anterior; c) o uso do conhecimento anterior tendo por base a resolução de um problema previamente definido.

\section{Conhecimento anterior empregado a partir de um paradigma}

Neste momento apenas desdobramos, com um exemplo histórico, a noção familiar de Kuhn e Laudan (já exposta resumidamente na primeira seção) de uma pesquisa baseada em um paradigma ou tradição de pesquisa.

Estabelecido a partir do século XVII, e desenvolvido no século XVIII, o programa de pesquisa ancorado na teoria do flogisto foi responsável por fornecer, para os químicos deste período, conhecimento teórico, técnicas experimentais e desenvolvimento experimental. A expressão "teoria do flogisto" é empregada pois um dos principais problemas da química era o da combustão (Maar, 1999, p. 453), o qual era explicado pela ação de um princípio: o princípio da inflamabilidade, denominado de "flogisto" pelo químico alemão Georg Stahl (1660-1734).

A vigência deste programa de pesquisa coincidiu com o desenvolvimento de uma importante área da química: a química pneumática, parte da química interessada em compreender os diferentes tipos de gases (ou "ares", como eram também chamados) que os químicos produziam e isolavam experimentalmente. Um destes químicos era o inglês Henry Cavendish (1731-1810), que produziu o que hoje conhecemos como hidrogênio, e foi por ele denominado de "ar inflamável".

Como o flogisto não havia sido identificado experimentalmente, ele era considerado um princípio da inflamabilidade, não o fogo em si. Cavendish, no 
entanto, julgava estar oferecendo uma contribuição ao programa de pesquisa do flogisto, e sugeriu que o ar inflamável seria o próprio flogisto (JUNGNICKLE e MCCORMMACH, 1999, p. 364). Do mesmo modo, outro grande teórico do flogisto - Joseph Priestley (1733-1804) - conseguiu isolar o que, desde Antoine de Lavoisier (1743-1794), se denomina de "oxigênio". Como os defensores do flogisto julgavam que o flogisto tornava o ar irrespirável, um ar respirável teria de ser coerentemente interpretado como um ar sem flogisto. O que Priestley isolou em seu laboratório era um ar respirável e portanto foi considerado um ar sem flogisto. Assim, os experimentos de Cavendish e Priestley faziam uso coerente de um conhecimento de fundo que os indicava de que modo interpretar seus resultados experimentais.

Conforme já assinalamos, a tradição de pesquisa da teoria do flogisto possibilitou um grande avanço nas técnicas experimentais; e, também como já vimos, os produtos deste avanço experimental eram coerentemente interpretados nos marcos referenciais da teoria do flogisto. Mas nem todos os cientistas desta época procederam deste modo. Um deles - Lavoisier - se notabilizou na história da ciência pela derrubada da teoria do flogisto, bem como pela sua proposta de uma nova química, o que gerou uma revolução científica na química (THAGARD 2007).

É comum se pensar que casos de revoluções científicas implicam em total abandono do conhecimento anterior. No entanto, estudos históricos têm mostrado que isto nem sempre ocorre.

Vimos que os teóricos do flogisto interpretavam seus resultados a partir de seu conhecimento anterior. Ora, experimentos muito semelhantes (se não iguais) foram interpretados de modo bastante diferente por Lavoisier. Tais interpretações constituíram uma parte importante da revolução química por ele conduzida: o ar inflamável de Cavendish, e o ar sem flogisto de Priestley vieram a ser considerados, no novo esquema conceitual de Lavoisier, respectivamente como hidrogênio e como oxigênio. Aparentemente, então, Lavoisier não estava empregando o conhecimento de fundo da química do flogisto, dado o fato óbvio de que era exatamente este conhecimento que, para ele, deveria ser abandonado. Além disso, uma outra razão para nos inclinarmos à ideia de que Lavoisier estava rompendo completamente com a química flogística é que ele defendia uma abordagem totalmente quantitativa, abordagem essa não completamente alinhada com os valores dos químicos do flogisto.

Contudo, apesar das incompatibilidades entre Lavoisier e os teóricos do flogisto serem evidentes, não se pode dizer que a ruptura teria sido completa. Em ao menos um aspecto se pode perceber que a química do flogisto teria sido empregada por Lavoisier: nos referimos aqui a algumas técnicas experimentais da teoria do flogisto que foram assimiladas e usadas por Lavoisier em alguns experimentos. Uma das fontes de Lavoisier foi exatamente Joseph Priestley, 
cujas técnicas experimentais foram utilizadas por Lavoisier (HOLMES, 1987, p. 95; IHDE, 1964, p. 68; BENSAUDE-VINCENT e STENGERS, 1992, p. 120; HUDSON, 1992, p. 67; THAGARD, 2007, p. 285).

Além disso, de acordo com o historiador Frederic Holmes, o rompimento de Lavoisier com a tradição do flogisto não pode ser descrito como uma "mudança" (Holmes, 1987, p. 95), desde que o processo transitório foi "prolongado, denso e complexo" (HOLMES, 1987, p. 95). E, como descreve eloquentemente Holmes: "Havia momentos (...) em que [Lavoisier] usava a expressão 'matéria do fogo' para se referir à sua própria concepção, outros momentos em que a usava como sinônimo de flogisto e às vezes ele não estava inteiramente certo sobre o que ela significava" (HOLMES, 1987, p. 95).

Para Thagard, Lavoisier, nos estágios iniciais de sua pesquisa, "delineia explicações stahlianas de alguns dos fenômenos que estava investigando" (2007, p. 284). Como ele argumenta (THAGARD, 2007, p. 284-285): "Portanto, claramente, ele tolerava a rede conceitual do flogisto e poderia aplicá-la, ainda que estivesse a desenvolver uma alternativa".

Neste sentido, mesmo uma ruptura conceitual como a promovida por Lavoisier pode incluir a noção de conhecimento anterior, desde que a noção seja localizada adequadamente pelo historiador e pelo filósofo da ciência. No caso de Lavoisier, então, teria ocorrido tanto uma continuidade - pois Lavoisier empregou métodos já usados pelos teóricos do flogisto - quanto uma ruptura.

\section{Conhecimento anterior como analogia}

Nem todo conhecimento anterior é empregado com base em estruturas conceituais plenamente consolidadas. Raciocínios analógicos, por exemplo, podem ser feitos na ausência de paradigmas ou tradições de pesquisa.

Um dos exemplos de uso de analogia como conhecimento anterior é o da analogia feita por Darwin entre seleção artificial e seleção natural. Darwin constatou que os criadores de animais, buscando um aperfeiçoamento de raças que eles domesticavam, selecionavam os melhores animais para a procriação; tal procedimento é exatamente o mesmo, argumentou Darwin, empregado pela natureza em sua seleção das variações úteis dos organismos; portanto a seleção natural (conceito que Darwin tentava estabelecer como científico) operaria do mesmo modo que a seleção artificial (conhecimento anterior disponível a Darwin) (DARWIN, 1872, p. 49). Como argumentou Darwin: "Não podemos supor que todas as variedades foram produzidas repentinamente, com a perfeição e utilidade que percebemos; de fato, em muitos casos, que sua história não é esta. A chave é o poder humano de seleção acumulativa: a natureza nos fornece variações sucessivas; o homem conduz tais variações conforme sua utilidade 
para ele" (DARWIN, 1872, p. 22). De acordo com Paul Thagard, a analogia darwinista teria uma finalidade explicativa: os fenômenos explicados pela hipótese da seleção natural são considerados do mesmo tipo que os fenômenos explicados pelo conhecimento anterior consolidado, da seleção artificial. Como coloca Thagard: "Explicações fornecem entendimento. Nós obtemos um maior entendimento de um conjunto de fenômenos se o tipo de explicação usado - o tipo de modelo - é similar aos já utilizados. Este parece ser o principal uso da analogia em (...) Darwin. [O] o valor explicativo da hipótese da evolução por meio da seleção natural é reforçado pela familiaridade com o processo de seleção artificial" (THAGARD, 1978, p. 91).

Tal analogia é amplamente reconhecida dentro da literatura. Este reconhecimento normalmente se dirige à dimensão epistemológica da analogia; ou seja: ao conhecimento que Darwin buscou na seleção artificial e humana operada pelos criadores. Enfatiza-se sobretudo o excepcional conhecimento que Darwin obteve em seus próprios experimentos com pombos, que mostraram a excelência de Darwin como cientista empírico e teórico (MARTINS, 2012, p. 109). Um aspecto epistemológico fundamental da analogia é o ganho explicativo que ela agregaria para a fundamentação de seu conceito de seleção natural, um conceito que - como a história mostrou - não seria de fácil assimilação. Para Mayr, Darwin, devido a suas dificuldades de produzir experimentação favorável à seleção natural, buscou na analogia suas evidências experimentais: "(...) como seria possível fazer um experimento com a evolução, quando as mudanças evolutivas são lentas? Foi nesse particular que Darwin se lembrou das atividades dos criadores de animais A seleção artificial, assim ele concluiu, era o análogo extremamente acelerado da seleção natural. Ela forneceu a prova experimental, de que tanto necessitava" MAYR, 1998, p. 543).

Percebemos que a discussão acerca da analogia está direcionada para a compreensão de aspectos epistemológicos nela envolvidos. Contudo, uma discussão interessante que poderia ser conduzida para compreendermos o papel das analogias em ciência seria a da identificação e desenvolvimento conceitual da dimensão pragmática da analogia. No caso de Darwin, de acordo com James Secord (1986), a analogia possui também uma dimensão social, pois, para compreendê-la, seria preciso inicialmente recuperar os interesses investigativos de Darwin, os quais, para o autor, podem ser assim apresentados: variação, herança, geração e seleção (SECORD, 1986, p. 519) ${ }^{6}$. Para Secord, estes interesses investigativos coincidiam com as realizações práticas dos criadores de animais; assim, num primeiro momento, a ideia geral de Darwin de que variações só interessam à medida que sejam herdadas (cf. DARWIN, 1872, p. 9) - contaria com um forte apoio da comunidade dos criadores. Estes, por sua vez, formavam grupos extremamente organizados (publicação de periódicos, organização de eventos etc), porém ainda não possuíam 
reconhecimento científico (SECORD, 1986, p. 521-522). Já Darwin era visto por eles como um naturalista respeitável (SECORD, 1986, p. 537). Deste modo, vincular-se a Darwin gerava uma série de benefícios institucionais para os criadores (SECORD, 1986, p. 537). Percebe-se portanto que a analogia entre seleção artificial e natural gerava também a constituição de uma rede colaborativa entre Darwin e os criadores.

\section{Conhecimento anterior tendo por base a resolução de um problema previamente definido}

De acordo com Karl Popper, a investigação científica começa com a identificação de um problema (POPPER, 1994, p. 247). Sem entrarmos aqui em detalhes acerca das dificuldades de generalizar a máxima popperiana diante dos registros históricos da ciência, diremos apenas que é possível aplicá-la em alguns casos. Um destes casos, particularmente, revela tanto que o início da pesquisa de fato se deu a partir de um problema, quanto que foi empregado o conhecimento anterior tendo por base a resolução de um problema previamente definido.

Este caso histórico é o da construção do modelo da dupla hélice do DNA. Diversas pesquisas paralelas indicavam, na década de 1940, a importância do DNA para explicações acerca da transmissão das informações genéticas. Tais pesquisas foram fundamentais para que um jovem biólogo americano - James Dewey Watson - assumisse a existência de um problema específico a respeito da função genética do DNA. E, de modo a solucionar este problema, foi traçada a seguinte estratégia: apresentar uma estrutura físico-química molecular para o DNA e, por meio desta estrutura, indicar de que modo a informação genética é transferida para moléculas associadas (RNA e proteínas). Esta estratégia era exclusiva, tendo sido empregada apenas por Watson e sendo posteriormente assumida por Francis Crick.

James Watson, trabalhando no Laboratório Cavendish a partir de 1951, em Cambridge, Inglaterra, conhece o físico Francis Crick. Juntos, conseguiram obter a estrutura do DNA em abril de 1953. Para isso empregaram diversos conhecimentos consolidados, dentre os quais um nos interessa de modo especial: as Regras de Chargaff.

Todos os pesquisadores que se dedicavam ao tema sabiam que o DNA era constituído por uma cadeia de fosfato (ácido fosfórico) e uma de açúcar (desoxirribose). Todos também sabiam que o DNA possuía bases químicas nitrogenadas (adenina, timina, citosina e guanina). A reunião do fosfato, açúcar e uma certa sequência específica de bases forma um nucleotídeo. As Regras de Chargaff indicam que as bases apresentam regularidade empírica, expressa na 
seguinte fórmula: $A T=1, C G=1$. Ou seja: em uma molécula de DNA a quantidade de adenina $(A)$ deve ser quase igual a de timina $(T)$, e a de citosina $(C)$ deve ser quase igual a de guanina $(G)^{7}$. O que ninguém na época sabia era como dispor tais elementos acima listados - em outros termos: o que ninguém sabia era de que modo o conhecimento consolidado deveria ser utilizado para se obter a estrutura do DNA.

Watson e Crick também não sabiam. Contudo, algo os diferenciava de todos os outros investigadores interessados na estrutura do DNA: para eles, a estrutura era apenas um meio para se obter uma pista acerca da função genética da molécula. Deste modo, seu problema era bastante diferente dos outros pesquisadores, os quais viam a estrutura como um fim científico por si só. $E$ foi exatamente o problema de Watson e Crick que os permitiu assimilar de um certo modo as Regras de Chargaff no interior de seu modelo do DNA, a dupla hélice do DNA.

Assumidas as regularidades de Chargaff, fica a questão de saber como as bases estarão dispostas no interior do DNA. Elas estabelecem relações químicas entre si por meio de ligações de hidrogênio. Mas como seriam tais ligações? Seriam ligações entre A e A, T e T e assim por diante? Seriam ligações entre A e T? Evidentemente, as leis da química ofereciam restrições que poderiam favorecer algumas exclusões; porém, uma série de possibilidades ainda estava em aberto, de modo que Watson e Crick tinham de optar por uma forma específica de arranjo molecular das bases.

Watson defendia a seguinte orientação geral: para que tivesse importância genética, o DNA precisaria se autoduplicar. Partindo de alguns dados empíricos produzidos pela biofísica Rosalind Franklin ${ }^{8}$, Watson e Crick adotaram o pressuposto de que uma molécula de DNA consistia de duas fitas, cada uma delas contendo uma sequência de nucleotídeos. Com base nas Regras de Chargaff, Watson e Crick propuseram originalmente que, se em uma fita o nucleotídeo tem a seguinte sequência de bases - A, T e $\mathrm{C}$-, a outra fita terá a sequência T, A e G (WATSON e CRICK, 1953b, p. 965). Neste momento Watson e Crick propuseram o inovador conceito de "pareamento": as bases se juntam em pares por meio das ligações de hidrogênio (WATSON e CRICK, 1953b, p. 965).

Porém, a noção de pareamento, tomada em seu sentido geral, ainda não resolvia o problema de Watson e Crick. Por que uma sequência qualquer de bases de uma fita - por exemplo, ATC - deveria ser pareada na sequência TAG na outra fita? Para responder a esta pergunta Watson e Crick ampliaram o conceito de "pareamento" e o transformaram em "pareamento complementar" (WATSON e CRICK, 1953b, p. 966): se não houvesse o pareamento, a informação genética contida no nucleotídeo da primeira fita não seria preservada na segunda fita. Assim, retomando o exemplo, se na primeira fita ocorresse ATC 
e na segunda fita ocorresse GCT, a informação genética que está em ATC seria perdida.

Vemos então que Watson e Crick, em seu uso das Regras de Chargaff, fizeram uso do conhecimento consolidado (expresso na regularidade empírica das bases) a partir do problema científico por eles eleito como central. Um aspecto essencial deste uso se localiza na natureza hipotética de seu modelo ${ }^{9}$. De acordo com Watson e Crick os dados empíricos poderiam revelar "uma sequência de bases muito irregular"; porém, uma explicação destes dados só seria fornecida assumindo-se o pareamento (Watson e Crick, 1953b, p. 965). E este pareamento, dado o problema por eles assumido, era essencial. Deste modo, não é que, num primeiro momento, Watson e Crick não poderiam parear A com A, ou A com $G$ etc. A verdade é que, assumido o problema de construir uma estrutura tendo a finalidade de apontar pistas para função genética do DNA, o pareamento deveria ser de A com T. Assim, o conhecimento anterior foi assimilado claramente de modo a favorecer uma solução para o problema de Watson e Crick ${ }^{10}$.

\section{Conclusão}

A classificação aqui apresentada teve como objetivo mostrar que a noção de conhecimento anterior pode ser compreendida em seus diferentes usos identificados por meio da história da ciência. Entendemos, é claro, que é possível sustentar a tese geral acerca da existência de tipos diferentes de conhecimento anterior; contudo, a lista aqui apresentada poderia ser quem sabe ampliada.

Mas, sendo ou não ampliada, a lista aqui apresentada já nos permite apontar para um problema que merece consideração. A ideia geral que subjaz ao conceito de conhecimento anterior é a de que a confiabilidade deste conhecimento é um guia seguro para a produção de novos conhecimentos. Isto, porém, na lista aqui apresentada, só se aplica ao primeiro caso: o de conhecimento anterior a partir de um paradigma. Nos outros dois casos conhecimento anterior como analogia e conhecimento anterior a partir de um problema científico prévio - tal segurança não se estabelece. Contudo, mesmo sem esta segurança, os cientistas ainda assim empregam conhecimentos anteriores.

Com isso fica sugerida a existência de um problema: o uso do conhecimento anterior se deve à confiabilidade de tal conhecimento (como no caso de Lavoisier) ou se deve à necessidade do emprego de tal conhecimento (como nos casos de Darwin e de Watson e Crick)? Ou ambos? Se a resposta for "ambos", não haveria necessidade de uma distinção conceitual entre tais usos? 
Entendemos que uma exploração destas questões pode auxiliar no esclarecimento da noção de conhecimento anterior.

\section{Referências bibliográficas}

BENSAUDE-VINCENT, B.; STENGERS, I. História da Química. Lisboa: Instituto Piaget, 1992.

BIRD, A. Inferência da Única Explicação. Cognitio, 15(2):375-384, 2014.

BOWLER, P. The mendelian revolution. Baltimore: Johns Hopkins University Press, 1989.

BOYD, R. Lex orandi est lex credendi. In: CHURCHLAND, P.; HOOKER, C. (eds.). Images of science. 1985. Chicago: Chicago Press. (p. 1-15).

CREAGER, A., MORGAN, G. After the Double Helix. Isis 99: 239-272, 2008.

DARWIN, C. On the Origin of Species. 6ª ed., London, John Murray, 1872.

FEYERABEND, P. Against Method. 4ª ed. Nova York: Verso Books, 2010.

GIERE, R. Science Without Laws. Chicago: The University of Chicago Press, 1999.

HARMAN, G. The inference to the best explanation. In: The philosophical review, $n^{\circ} 74$, p. 88-95, 1965.

HOLMES, F. Lavoisier and the Chemistry of Life. Madison, The University of Wisconsin Press, 1987.

HUDSON, J. The History of Chemistry. New York: Chapman \& Hall, 1992.

IHDE, A. The Development of Modern Chemistry. Nova York: Dover, 1964.

JUNGNICKLE, C, MCCORMMACH, R. Cavendish: The Experimental Life. Lewisburg, Bucknell University Press, 1999.

KLUG, A. Rosalind Franklin and the Double Helix. Nature 248: 776-79, 1974. 
KUHN, T. A Estrutura das Revoluções Científicas. São Paulo: Perspectiva, 2000.

LADYMAN, J., DOUVEN, I., HORSTEN, L., VAN FRAASSEN, B. "Uma Defesa da Crítica de van Fraassen à Inferência Abdutiva: Uma Réplica a Psillos". Tradução de Marcos Rodrigues da Silva e Alexandre Meyer Luz. In: Crítica. vol. $6, n^{\circ} 21$, p. $63-88,2000$.

LATOUR, B. A Ciência em Ação. São Paulo: Unesp, 2000.

LAUDAN, L. Progress and Its Problems. London: Routledge, 1997.

LEPLIN, J. A novel defense of scientific realism. Oxford: Oxford University Press, 1997.

LIPTON, P. Inference to the best explanation. 2. ed. London: Routledge, 2004.

LIPTON, P. O melhor é bom o suficiente? Tradução de Marcos Rodrigues da Silva e Alexandre Meyer Luz. In: Princípios, vol. 17, n² 27, p. 313-329, 2010.

MAAR, J. Pequena História da Química: Primeira Parte: dos Primórdios a Lavoisier. Florianópolis: Papa-Livro, 1999.

MADDOX, B. Rosalind Franklin: The Dark Lady of DNA. New York: Harper Colins, 2002.

MARTINS, R. "A origem dos pombos domésticos na estratégia argumentativa de Charles Darwin”. Filosofia e História da Biologia, vol. 7, n. 1, p. 91-116, 2012.

MAYR, E. O Desenvolvimento do Pensamento Biológico. Brasília: UNB, 1998.

NULAND, Sherwin. A peste dos médicos. São Paulo: Companhia das Letras, 2003.

OLBY, R. Charles Darwin's Manuscript of Pangenesis. The British Society for the History of Science, 1(3):251-263, 1963.

OLBY, R. The Path to the Double Helix. London: MacMillan, 1974.

POLCOVAR, J. Rosalind Franklin and the Structure of Life, Greensboro, Morgan Reynolds, 2006. 
POPPER, K.R. Conjecturas e Refutações. Brasília: UNB, 1994.

PSILLOS, S. Sobre a crítica de van Fraassen ao raciocínio abdutivo. Tradução de Marcos Rodrigues da Silva e Alexandre Meyer Luz. In: Crítica., vol. 6, nº 21, p.35-62, 2000.

SAYRE, A. Rosalind Franklin and DNA. New York: W.W. Norton \& Company, 1975.

SECORD, J. "Darwin and the Breeders: A Social History". The Darwinian Heritage. (ED. Kohn, David) Princeton: Princeton University Press, 1986.

SELYA, R. Defined by DNA: The Intertwined Lives of James Watson and Rosalind Franklin. Journal of the History of Biology 36: 591-97, 2003.

STANFORD, K. Exceeding our grasp. Oxford: Oxford University Press, 2006.

THAGARD, P. “A Estrutura Conceitual da Revolução Química”. Princípios, v. 14, n. 22, p. 265-303, 2007.

THAGARD, P. The best explanation: criteria for theory choice. In: The journal of philosophy. Nova York, Columbia University. 1978. (vol. LXXV, $n^{\circ}$ 2, p. 76-92).

VAN FRAASSEN, B. A imagem científica. Tradução de Luiz Henrique Dutra. São Paulo: Discurso Editorial, 2007.

WATSON, J., CRICK, F. A Structure for Deoxyribose Nucleic Acid. Nature 171:737, 1953a.

WATSON, J., CRICK, F. Genetical Implications of the Structure of Deoxyribose Acid. Nature 171: 964-967, 1953b.

WATSON, J. The Double Helix. London: Weidenfeld \& Nicolson, 1997.

\footnotetext{
${ }^{1}$ A expressão "conhecimento anterior" é uma tradução da expressão inglesa "background knowledge", por vezes traduzida também, de um modo literal, como "conhecimento de fundo". Outra opção seria usar "conhecimento consolidado" ou mesmo "conhecimento anterior consolidado".

${ }^{2}$ Foram consultados, para este artigo, os seguintes dicionários: A Companion to Epistemology (Blackwell), A Companion to the Philosophy of Science (Blackwell), A Companion to the Philosophy of Science (Routledge), The Continuum Companion to the Philosophy of Science (Bloomsbury Academic) e Stanford Enciclopedia of Philosophy (on line). Ainda que a amostragem seja pequena, entendemos que ela é
} 
significativa. Consultamos também diversas coletâneas de filosofia da ciência, e não localizamos nenhum artigo com uma discussão específica sobre o conhecimento anterior.

${ }^{3}$ A formulação original do argumento da inferência da melhor explicação se encontra em Harman (1965).

${ }^{4}$ Os outros dois são: consiliência e simplicidade.

${ }^{5}$ Além disso, são raras as críticas à noção de conhecimento anterior. Uma delas se encontra na filosofia da ciência de Paul Feyerabend, e diz respeito ao surgimento de novidades científicas. Considerada como um critério para avaliar a legitimidade explicativa de uma nova hipótese, a compatibilidade dessa nova hipótese com o conhecimento anterior (compatibilidade denominada por Feyerabend de "condição de consistência") (FEYERABEND, 2010, p. 17) pode, no entender de Feyerabend, dificultar a produção de novas evidências. O que ocorreria, ainda de acordo com Feyerabend, seria que novas hipóteses poderiam deixar de ser aceitas não em função de seu desacordo com os fatos, mas pelo seu desacordo com o conhecimento de fundo consolidado. Por isso, para Feyerabend, deve ocorrer uma proliferação teórica: várias teorias devem ser aceitas como propostas iniciais, e não apenas as compatíveis com o conhecimento anterior. Não analisaremos a crítica de Feyerabend, considerando o contexto de nosso artigo. (Um ponto incidental da proposta de Feyerabend é que ela, em parte, está em bastante sintonia com o realismo científico: a busca de proliferação teórica. Contudo, realistas aceitam a proliferação somente para casos de compatibilidade com o conhecimento anterior (LIPTON, 2004, p. 59; BIRD, 2014, p. 377).)

${ }^{6}$ A existência destes interesses é também validada por outras fontes na historiografia. Sobre isto ver STANFORD (2006, p. 62), BOWLER (1989, p. 23; 58) e OLBY (1963, p. 251).

${ }^{7}$ Esta regularidade empírica foi proposta pelo bioquímico Erwin Chargaff ao final da década de 1940.

8 Discussões acerca da participação de Rosalind Franklin na construção do modelo da dupla hélice podem ser conferidas em SAYRE (1975), MADDOX (2002), POLCOVAR (2006), OLBY (1974), CREAGER e MORGAN (2008), KLUG (1974) e SELYA (2003).

${ }^{9}$ É importante ressaltar que Watson e Crick entendiam seu modelo como uma hipótese (WATSON e CRICK, 1953a, p. 737; WATSON e CRICK, 1953b, p. 965).

${ }^{10}$ Watson e Crick entendiam que de nada valeria propor um modelo para o DNA caso ele se revelasse uma molécula geneticamente desinteressante. Como revela WATSON (1997, p. 147): "Tinha havido dias em que Francis e eu nos incomodávamos [com a possibilidade] de que a estrutura do DNA se revelasse superficialmente muito monótona, não sugerindo nada a respeito de sua replicação ou de sua função em controlar a bioquímica". 